\title{
Recognising poor black youth from rural communities in South Africa as epistemic contributors
}

\author{
Mikateko Mathebula \\ University of the Free State \\ Corresponding Author: HoppenerM@ufs.ac.za
}

(Submitted: 13 May 2019; Accepted: 21 June 2019)

\begin{abstract}
In South Africa, students who are poor, black and come from rural communities with poorly resourced schools are vulnerable to being victims of epistemic injustice. This is because they are usually seen as under-appreciated knowers who have low (English) language proficiency and deficits in academic literacy. In an attempt to provide a nuanced characterisation of youth from rural areas, this paper reflects on one student's life-history interviews and his photo- story that form part of data collected since 2017 for Miratho - a project on achieved higher education learning outcomes for low-income university students. The paper uses a capabilities approach as an interpretive framework for the qualitative data and theorises that students' linguistic capital and narrative capital are epistemic materials that can be mobilised into the 'capability for epistemic contribution' as conceptualised by Miranda Fricker. The paper thus makes a case for higher education researchers and educators to recognise poor black youth from rural communities as both givers and takers of knowledge or 'epistemic contributors'. It argues that doing so constitutes an ethical response to the structural inequalities that limit equitable university access and participation for youth in this demographic.
\end{abstract}

Keywords: Capability approach, epistemic contribution,higher education

\section{Introduction}

In South Africa, poverty has a spatial dimension; it remains concentrated in rural areas that were previously segregated along ethnic lines during apartheid and set aside for black people (Walker and Mathebula, 2019; Sulla and Zikhali, 2018). Today, rural communities account for $61 \%$ of the poverty burden (Moses et al., 2017). The provinces with the largest concentrations of people living in poverty are KwaZulu-Natal, Limpopo, and Eastern Cape. In relation to schooling, these three provinces have both the lowest Grade 12 results and the highest dropout rates (Metcalf, 2019).

The rural context thus presents a major challenge for learners who might aspire to go to university, and it has a negative effect on higher education access more broadly (Walker and Mathebula, 2019). Learners who manage to get a bachelor's pass and qualify for university 
entry, are more likely to face persistent challenges that require constant struggle to succeed. This is because they usually attend poorly-resourced schools that may not have prepared them well enough for university study. In addressing the academic under-preparedness of such youth, academic development policies and practices often emphasise student deficits by constructing a view of students as individuals who lack language skills and lack the ability to think critically and conceptually (Boughey, 2005). This deficit view of students has created a 'crisis discourse' (Calitz, 2018a) that centres on the worst-case scenario in pointing to examples of 'illiteracy' and under-preparedness of university students, to justify remedial interventions (Leibowitz, 2011). This discourse is also strengthened by a homogenized view of all students struggling to the same degree and with the same 'problems', instead of acknowledging differences associated with access to resources or structural limitations (Wilson-Strydom, 2015).

However, literature on low-income and working-class students in higher education has begun to challenge pervasive stereotypes about ability and deficit by highlighting multidimensional inequalities within university life (Calitz, 2018a). Scholars have brought a class-based analysis to the conversation about access to higher education in order to foreground how cultural capitals, resource inequality, and invisible privilege alienate lowincome and working-class students from universities (Calitz, 2018a). This research has been carried out in different contexts like the UK (see Archer et al., 2003; Bathmaker et al., 2016) the USA (see Jack, 2019) and South Africa (see Cross, 2018; Cross and Atinde, 2015). In these studies, scholars have drawn on theories of justice (e.g. Rawls, 1971; Young, 1990; Dworkin, 2002) to incorporate discussions on the importance of recognition and distributional justice, foregrounding that inequality carries normative value; it represents undesirable conditions that constitute social injustice, and, therefore, requires ethical responses beyond resource distribution (Sayer, 2005).

Inspired by this literature, this paper advances the argument that universities should enhance the valued freedoms or 'capabilities' (Sen, 1999) of low-income youth from rural communities, as an ethical response to structural inequalities that pervade the higher education space and society more broadly. In particular, the paper considers how universities can create effective opportunities for rural youth to mobilise their skills, experiences, and ways of seeing the world or their 'capitals' (Yosso, 2005) into both taking from shared pools of knowledge, whilst giving to them at the same time - thus making 'epistemic contributions' (Fricker, 2015). Attention is drawn towards the effective opportunities rural youth have to make epistemic contributions for three reasons. First, although there is increasing literature that encourages us to acknowledge that youth from poor or low-income and working class backgrounds have valuable capitals that they can mobilise for gaining university knowledge (see Calitz, 2018a; Janse van Rensburg and Kapp, 2015; Leibowitz and Bozalek, 2015), not much has been written about the importance for these capitals to be mobilised into the giving of knowledge. Second, exploring how this bi-directional and reciprocal way of creating knowledge is facilitated through universities is crucial, because it can tell us how inclusive knowledge-making processes in higher education institutions are, which can be viewed as a proxy for how socially just our 
higher education system is. Thirdly, it can help us to scrutinise who we listen to, and who gets to add their views and values to public knowledge that is treasured and genuinely engaged with in universities, which is a locus of epistemic relational equality and inequality (Fricker, 2015; Pohlhaus, 2011).

\section{Context}

For low-income rural youth in universities, structural inequality plays out not only in how resources and opportunities are distributed unfairly amongst a diverse student cohort (Sayer, 2005). It also plays out in how relational, dispositional and cultural aspects of learning have an effect on students' ability to participate as equal members of a university (Pohlhaus, 2011; Sayer, 2005). The fairer distribution of material resources and recognition by valued others, is pertinent to the experiences of low-income and first-generation students from rural communities (Sayer, 2005; see also Walker, 2008). This is because it enables epistemological access, defined by Morrow (2009) as entry into educational settings that goes beyond institutional or formal access to include access to the knowledge produced by such institutions and the mechanisms they use to distribute it. Acknowledging rural students' potential to succeed is necessary not only as a way of countering the effects of historic distributional inequality, but also as a means to avoid misrecognition that diminishes human dignity instead of enhancing it. As Leibowitz (2009) argues, students bring various forms of capitals to pedagogy, but the contextual challenges that they face to attain institutional belonging may negatively affect their engagement with learning. This perspective acknowledges that language, identity, race, and socioeconomic class (and gender) are interconnected factors that shape the experience of being a university student especially in South Africa.

A number of researchers have used in-depth narrative and biographical methodologies to establish the material, cognitive and affective issues that influence teaching and learning for vulnerable students (see Boughey, 2005; Leibowitz, 2009; Marshall and Case, 2010; Oana, 2016; Timmis and Muhuro, 2019). Understanding students' biographies creates more room for nuanced understandings of struggle for academic success and its impact on students' lives (Goodson and Sikes, 2001; Jones, 2011). For example, taking into account the lack of resources at schools and communities where low-income youth were before they entered university, offers insight into the resource scarcity that they face. Yet, it also suggests that they have capitals that have been fostered through their persistent negotiation of these challenging environments (Calitz, 2018a; Janse van Rensburg and Pym, 2015; Marshall and Case, 2010). That is, when students face barriers in accessing higher education, they bring agency, resilience and reflexivity to the institution as they learn to negotiate new ways of thinking and being (Calitz, 2018a; Janse van Rensburg and Kapp 2015; Leibowitz and Bozalek, 2015). All of this tells us that we should resist simplistic, anecdotal, empirically unfounded characterisations of (black) low-income youth in the post-apartheid context (Soudien, 2007).

In order to provide a better grounded characterisation of South African youth, one which is based on reflections drawing from qualitative evidence, this paper builds on the work of 
Yosso (2005) who argues that we can learn from the range of cultural knowledge, ingenuity, capacities and networks possessed by socio-economically marginalized groups that often go unrecognized. Forms of capital fostered through cultural wealth that low-income rural South African youth might bring with them to university include 'aspirational, navigational, social, linguistic, familial and resistant capital' (Yosso, 2005: 69). Reflecting on evidence from one student's life history interviews and his photo-story, I discuss examples in the data that indicate his linguistic capital (Yosso, 2005) and narrative capital (Watts, 2008). I focus on these capitals mainly because this demographic of students is typically seen as having major deficits in (English) language proficiency and therefore deficit in academic literacy. By drawing attention to their linguistic and narrative capitals, I demonstrate that being less proficient, or less articulate in English, does not mean that students do not have other valid means of rendering their knowledge intelligible.

While the literature discussed in this section reveals that various capitals are mobilised by students to gain epistemic access (see Cross, 2018) this paper argues that these capitals can also be mobilised to make epistemic contributions (Fricker, 2015). That is, students' capitals are not only useful in terms of them taking or getting knowledge from universities, but also valuable because they can enable students to give knowledge in the process of taking it, to be both givers and takers of knowledge, to be both knowers and tellers or 'epistemic contributors'. In order to make this point, I theorise the value of students' linguistic and narrative capitals in a higher education setting using Amartya Sen's capability approach (Sen, 1999) as an interpretive framework. By so doing, I hope to achieve two related aims of this paper: First, to make a case for higher education researchers and educators to recognise poor black youth from rural communities in South Africa as epistemic agents (Elgin, 2013) and epistemic contributors (Fricker, 2015). Second, to explain how doing so creates conditions for the social uptake of 'disadvantaged' students' contributions to knowledge, thereby constituting an ethical response to the structural inequalities that render them 'outcasts of the public economy of authority and credibility' (Schuppert, 2015: 124).

\section{The Miratho Project}

Working with the youth-led NGO Thusanani Foundation, our four-year (2016-2020) mixed methods research project investigates the multi-dimensional factors and dynamics that shape low-income rural and township students' effective opportunities to access universities, participate and flourish in them, and move from higher education to employment.

Complex data sets consisting of both quantitative and qualitative data are being gathered in our project, which will enable a macro view of the educational pathways of the selected student population (64 students) but also fine-grained micro accounts of their lives. Our data sets include life history interviews, photovoice data in the form of photo-stories on exclusion and inclusion at university, a capabilities-based 'achieved learning outcomes' survey, and statistical data from the Higher Education Management Information System (HEMIS). These data are required to address the objectives of our project because we know that the 
distribution of opportunities is not only embedded in university educational and social arrangements, but also in families, schools and local communities. Insights into these societal dynamics are also being gained by exploring student pathways, experiences, aspirations and plans for their future careers. Additionally, we are exploring students' values and commitments to contributing to an inclusive society, and what creates and sustains these values. Moreover, students have been involved in participatory research processes in the form of photovoice (Wang and Burris, 1994, 1997) so that the project directly expands their capabilities, operationalizes their right to research (Appadurai, 2006) and, by recognising and engaging them as co-researchers, contributes to more epistemic justice (Martinez-Vargas et al., 2019).

We have been working with 64 low-income students, who are now in their third or fourth and final year of undergraduate study. They are enrolled in a variety of disciplines at five diverse universities across four provinces: Limpopo, Gauteng, Eastern Cape, and the Free State. Most of them come from the poorest areas in the country, namely Vhembe district (Limpopo), Joe Gqabi district (Eastern Cape), and Harry Gwala district (KwaZulu-Natal), and attended quintile 1 to 3 non-fee paying public schools, which serve low-income communities and lag behind well-off schools in learning outcomes (Walker and Mathebula, 2019). For example, Grade 9 pupils in poor, mostly black schools have a backlog of approximately three and half years relative to those in well-off schools (see Moses et al., 2017).

As mentioned before, for the purposes of this paper I will focus on just one student, drawing on excerpts from the life history interviews and sharing some reflections on the value of the photovoice strand of our project. Before I do this, the capability approach and its value as a normative and interpretive framework in educational research is discussed.

\section{The capability approach}

The capability approach (Sen, 1999, 2003) is a broad normative framework rooted in a philosophical tradition that values individual freedoms, and is used for the evaluation and assessment of individual wellbeing, social arrangements and the design of policies and proposals about social change (Alkire, 2002). It provides an alternative view of development by conceptualising development as freedom (Sen, 1999) and the core focus of the approach is on the effective opportunities people have to be and to do what they have reason to value (Robeyns, 2005). It highlights the difference between what is effectively possible, or substantive freedoms (known as 'capabilities'), and outcomes or what is actually achieved (known as 'functionings'). The capability approach can also be described as a wide ranging normative framework which can be used either to tell us what information we should look at if we are to judge how well someone's life is going or has gone, or as an evaluative framework within which to conceptualise, measure and evaluate wellbeing (Crocker and Robeyns, 2010).

The capability approach also provides a framework for an examination and understanding of the purposes of universities because it encourages us to consider individual opportunities for wellbeing achievement in higher education. This is because it defines development as pertaining to positive processes of social, economic and political change that 
broaden valued opportunities (Alkire, 2002; Sen, 2003). As such, through a capabilities lens, higher education is not solely a means for individuals to achieve economic gains through gaining knowledge and skills for employment. Instead, the approach inspires us to ask how higher education is contributing to human development, by broadening individual capabilities and functionings that people have reason to value. The usefulness of the capability approach in this regard is demonstrated in a number of studies that employ it as a theoretical lens for researching higher education in the South African context. Issues explored in such studies include diversifying university access (see Walker, 2008; Wilson-Strydom, 2015); what universities can do to enhance first generation students' freedom to flourish (see Calitz, 2018a); the higher education aspirations of migrant youth in South Africa (see Mkwananzi, 2019); the higher education experiences of students with disabilities (see Mutanga, 2019); or the education of engineers (Mathebula, 2018). These studies, which examine higher education phenomena through the lens of the capability approach, show its theoretical richness to aid in conceptualizing and articulating normative accounts of the changes that need to take place in universities if they are to contribute to human development and social justice. The literature demonstrates that using the capability approach as a theoretical lens for higher education research is valuable because it points to enhancing different dimension of wellbeing for all people, in its normative account of development.

Similar to the studies mentioned above, this paper's interest lies in considering how universities can enhance the capabilities of low-income youth from rural communities, as a way of achieving more equity in higher education. As mentioned before, I am interested in how universities can create effective opportunities for rural youth to mobilise their capitals into valuable capabilities, with a particular focus on the capability for epistemic contribution (Fricker, 2015). This interest is stimulated by the fact that there is a lack of literature on the potential for these capitals to be mobilised into the giving of knowledge, while there is more on how they are mobilised into the taking of knowledge. Moreover, epistemic contribution has been conceptualised convincingly as a core human capability by Fricker (2015), while Walker (2019) has made a compelling case for its consideration as a foundational capability in education.

\section{The capability for epistemic contribution}

According to Fricker (2015) there are two kinds of epistemic giving that together describe a capability that is possibly essential to human flourishing, the giving of:

- Informational materials - information itself, but also anything bearing on the question at hand, like evidence, critical doubt, hypothesis, argumentation etc. and

- Interpretive materials - anything necessary to make sense of the social world, like different understandings, but also anything related to how this understanding is justified or how reasonable it is, such as the concepts, theories or lenses used to conceive it (Fricker, 2015). 
This epistemic giving requires having the internal ability for forming and sharing beliefs about the world, including the interpretation of one's social world, in the presence of the minimal social uptake required to be able to make epistemic inputs without having them rejected on the grounds of testimonial or hermeneutical injustice (Fricker, 2015). Testimonial injustice occurs when a person offers their view on something but receives a low level of credibility due to prejudice on the hearer's part (Fricker, 2015). For example, when undergraduate students' views on poverty are not taken seriously because students are not seen in the same light as academic experts who research poverty or structural inequalities. In this case, the hearer may not recognise students as credible knowers, because they lack knowledge and expertise in researching conditions of poverty, and the hearer may dismiss anything students say on this topic as a result. On the other hand, hermeneutical injustice occurs where a pervasive absence of shared interpretive tools makes it difficult for the speaker's social experience to be understood (either by the hearer or even by the speaker herself) thus wronging them in their capacity as a giver or producer of knowledge (Fricker, 2015; also see Mason, 2011; Crerar, 2016; Coetzee, 2018). Forms of epistemic injustice include wilful ignorance of marginalised group' hermeneutical resources (Pollhaus, 2011), the ill distribution of epistemic goods (Dotson, 2012), and the undermining of one's ability to participate in inquiry (Coady, 2012). For example, students who are knowledgeable about poverty based on their personal experience might be recognised as credible knowers because of this, but may still suffer epistemic injustice due to not having access to particular kinds of informational and interpretive materials - before they enter university - to render their understanding intelligible to themselves or others. These epistemic materials include a rich English vocabulary; knowledge drawing from theory on power, poverty, and inequality; debating, academic writing, or public engagement skills; and so forth. As Fricker (2015) argues, in order for everyone with relevant informational and interpretive materials to be included in knowledge making, conditions for the social uptake of epistemic contribution need to be in place. Although the conditions vary contextually, they always require social arrangements that ensure, within reason, that we do not reject or discredit epistemic inputs owing to our prejudiced assessment of the speaker, or the speaker's inability to render their thoughts intelligible (Fricker, 2015).

While some people, such as academic experts, are enabled by evenly spread social uptake to make their epistemic contributions across the board, others, such as undergraduate students, may find their capability diminishes or disappears altogether in some situations. In the case where it disappears altogether, students still have and practice the 'internal' capability for forming epistemic inputs that are worth gathering, but a lack of social uptake means that we deny them effective opportunities to make those contributions, and so their input does not make the pool of shared knowledge.

As Fricker (2015) says, we should not prevent anyone with relevant epistemic materials to offer from contributing to shared knowledge for 'epistemically irrelevant' reasons (at least not without an appropriately overriding reason). This requires us to construct conducive conditions for social uptake. That is, creating learning environments within universities (and social 
arrangements in broader society) where contributing to knowledge pools and taking from them happens more equally (Fricker, 2015).

In defending epistemic contribution as a foundational capability in education, Walker (2019) argues that it should be secured through relevant functionings and be practiced iteratively in the space of education. She also proposes that we evaluate not only whether the opportunity to develop this capability exists, but also whether the space to exercise and refine it in practice is in place. That is, we also need to assess whether students have the space to 'think, theorise, interpret the world, develop methodologies and write from where [they are] located (Ndlovu-Gatsheni, 2018: 17).

\section{Student capitals as sources of relevant epistemic materials}

So, what do students (in this case poor, black students from rural communities) have to contribute to shared pools of knowledge that we produce within and through universities? This section discusses two capitals that seem to have manifested as relevant sources of epistemic material for Rimisa ${ }^{1}$ : narrative and linguistic capital; thus, providing examples of what we might consider as evidence of the capitals of which Yosso (2005) and Watts (2008) speak. The excerpts discussed as evidence of these capitals (as discussed below) are from life history interviews carried out in 2017 and 2018 with Rimisa. I also draw from and analyse his photostory as part of this evidence.

Rimisa comes from a rural village in Tshipise Sagole, which is located in one of the poorest districts in the country; Vhembe District in Limpopo province. Rimisa is a part of a family of 15 . He grew up under extreme poverty ('we can spend maybe more than three days [...] being food insecure, yes'). This is in part because his mother is deceased ('She was working in the kitchen'), but also because the family is large and his father ('a self-employed vegetable salesman') makes very little money. His father used to receive R5000 per month on a type of disability grant from his former Johannesburg employers, but this payment stopped in 2016 resulting in more hardship for the family ('Even to meet the basic needs, it was difficult for us').

High school was challenging for Rimisa. He had no support or encouragement from his father to complete matric. He did not have friends, although he spent a lot of time at school ('I was lonely, no one was supporting me'). He left home at 06:30am and returned at 05:30pm, spending much of this time reading. He did this to minimise time spent at home. Rimisa started thinking about going to university in grade 8 . He only applied to Country University ${ }^{2}$. It was a complicated process for him. He had limited information, did not know where to get application forms for admission and for bursaries, and he struggled to raise the R100 application fee. Although his high school was not well resourced, his teachers played a big role in him completing high school with good grades and getting him into university. They motivated and encouraged him to do well. They supplied him with an application form for Country University and gave him the R100 to submit the application. Rimisa completed his

\footnotetext{
'Rimisa' is the student's pseudonym

${ }^{2 .}$ Country University' is a Pseudonym for an historically disadvantaged university in Limpopo
} 
matric at Hanyani Secondary School (quintile $2^{3}$ ) in 2015. His highest grade was $80 \%$ in Tshivenda (Home Language). His lowest, 60\% in English (First Additional Language) which he described as a struggle to achieve. At the time of the interview in 2017, Rimisa was 20 years old, in his second year of a four-year Indigenous Knowledge Systems (IKS) BachelorDegree at Country University. He is funded through the National Student Financial Aid Scheme (NSFAS). $\mathrm{He}$ is the first person, in his immediate and extended family, to go to university.

\section{Linguistic capital}

Linguistic capital refers to having multiple language and communication skills (Yosso, 2005). It includes the intellectual and social skills attained through communication experiences in more than one language and/or style (Yosso, 2005). It often entails experience as engaged participants in storytelling traditions that may include listening to and recounting oral histories, parables, stories and proverbs (Yosso, 2005). As such, linguistic capital is not only linked to communication skills beyond language mastery, but it can involve skills in approaching people, establishing and maintaining relationships with them, a willingness to learn from those who are different (in terms of their age, gender, race, worldview etc.). Therefore, it is reasonable to assume that it might have a bearing on one's willingness and ability to work with and value diverse people (which is a valuable higher education learning outcome or attribute). Consider the example that Rimisa gives:

By the time I'm at home I spend my time asking people information, because when I was defining this IKS I said it's a cultural studies, so as for me, I'm still young. I don't have that much about culture, about different cultures. So, I go maybe to...you know, to old ladies and ask them information about the culture....and let me say almost every day I'm always adding some information in the lecture because I go out (...) and ask people about... I ask people information about IKS. So, when I'm in class I'm having something [to share].

This excerpt suggests that Rimisa acknowledges the value of epistemic inputs that can be made by people who provide a different perspective i.e. the 'older women', which requires recognising them as trusted knowers so that he in turn is willing to listen to what they have to say. Too often, we focus on how knowledge is created through 'speaking', without acknowledging the role of the listener in the process of knowledge production. I will return to this point later.

It is important to note that in the above excerpt, Rimisa is not referring to something he did as part of a research assignment. He approached community members and initiated

\footnotetext{
${ }^{3}$ The South African quintile system ranks schools in five bands according to their infrastructure and location. Formerly white schools (model C) located mostly in urban and suburban areas fall into quintiles four and five, and charge school fees. Fee-free public schools that serve low-income communities are usually found in rural and township areas and fall into quintiles one to three. School quintiles are thus a rough proxy for socio-economic conditions and quality of schooling.
} 
conversions with them about indigenous knowledge on his own accord. This demonstrates his eagerness to learn and ability to identify community members who might be informative or help him understand his subject matter better. It also important to note that Rimisa uses Tshivenda in the community when approaching people for their views on indigenous knowledge or cultural practices, but shares what he learns in English in class, despite having struggled with English proficiency in high school and only learning to speak it fluently during his first year of university:

When it comes to English, yes, I was passing, but by using cramming methods, yes, because my language, my English language was poor. I started to learn English this year, last year [first year of university]. That is how I learned...I started to talk English. And when it comes to... Even in my results for grade 12 or, let's say, from grade 8 to 12, my English was very poor. I didn't pass it well. The only time that I passed it well was in grade 12. I got 60, and it was minimum in my statement, but in other subjects I was very good.

Rimisa was aware of the importance of doing well in English in order to be able to learn at university, and he admits that the transition from communicating solely in Tshivenda to using English was difficult:

When I was in grade 12 people were saying, to be in tertiary institution is very difficult because at first you live in Limpopo, you are... your [English] language is poor. It means when the lecturer is lecturing you won't understand anything. That was my problem.

Although it might be reasonable to expect university entrants to be proficient in English because it is the national medium of instruction in South Africa, it is unreasonable to assume that low English proficiency is an indication of one's intelligence or to assume that one lacks other tools to render their knowledge intelligible. In Rimisa's case, his seeking epistemic inputs from community members using his home language, translating, or making sense of this, and sharing what he learns with his classmates in English, constitutes linguistic capital which he mobilises into taking and giving from a shared pool of knowledge. Of course, the possibility that he is misinformed by the people he speaks to in the community exists, or that his interpretation may misalign with the intended meaning. But what is important in this instance is Rimisa's capacity to act as an epistemic contributor without being dismissed as a mistrusted knower, or discredited as an incapable teller on the basis of his educational (quintile 2 school) cultural or linguistic or demographic (young, black, male, South African, low-income) background.

\section{Narrative capital}

Narrative capital is a more specific form of linguistic capital, it refers to 'a particular form of storytelling capital' (Watts, 2008). Telling stories is a fundamental human activity, a means by 
which we represent ourselves to others and make sense of our lives. Moreover, narrative modes of thought can be seen as a particular form of human knowledge - 'narrative cognition' (Bruner, 1986: 1987). In this conceptualisation, Bruner contrasts narrative cognition to scientific (positivist) modes of producing or sharing knowledge, which often dominate discussions of epistemology (Marshall and Case, 2010). If we consider narrative modes of thought as forms of human knowledge, then storytelling can be understood as a valid conduit for sharing social knowledge or making epistemic contributions. As Watts (2008) argues, everyone has a story to tell, but the different lives that inform and frame the stories we tell of ourselves are valued differently. Therefore, the power to tell one's own story lies in two interrelated aspects of storytelling: the value of the story, and the way one tells it (Watts, 2008). However, the power to tell stories is rendered meaningless in the absence of 'narrative capability', or the real opportunities individuals have to tell their stories (Watts, 2008). That is, individuals may have reserves of narrative or linguistic capital; but be unable to make use of it because they are not given effective opportunities to tell their stories, particularly if a necessary condition of this narrative capability is the freedom to be listened to (Watts, 2008).

As mentioned before, students in the Miratho project have been involved in participatory research processes in the form of photovoice. Participatory photography in a variety of forms e.g. photo elicitation (Harper, 2002; Leonard and McKnight, 2015), photo novella (Wang and Burris, 1994), or photovoice (Wang, 1999, 2006) emerged in the 1990s reflecting the turn from documentary photography to more reflexive approaches (Mikhailovich et al., 2015). Participatory photography emphasises the active role of research participants in the generation and interpretation of photos (Mikhailovich et Al., 2015). Used as a method in social research (e.g. in areas of healthcare, homelessness, and education) and in development studies (Gervais and Rivard, 2013; Marion and Crowder, 2013; Sutton-Brown, 2014) usually, photographs are used to elicit information to inform research and as tools to stimulate self-reflection and interactions with others (Mikhailovich et al., 2015).

Photovoice draws on Freire's (1970) philosophy of problem-posing education, by using photographs to foster critical analysis of social problems and collective action (Mikhailovich et al., 2015). It is based on the idea that photographs can enable and facilitate discussion and can assist people to explore solutions to challenges they may be facing (Mikhailovich et al., 2015). In photovoice projects, facilitators usually give cameras to research participants and ask them to document various aspects of their lived experiences through photography (Latz et al., 2016). The photos are used to elicit analytic discussions during focus groups or interviews with members of the research team, where participants narrate the personal significance of the images (Latz et al., 2016). Typically, photovoice involves working collaboratively with small groups over a period ranging from weeks to months, as this extended engagement contributes to building trust and group familiarity (Mikhailovich et al., 2015). Although the use of participatory and visual research methods is gaining traction, and it is popular in research with youth (e.g. Oana, 2016) photovoice has not been that widely used in the area of higher education. In our project with rural and township youth, we used an adapted form of 
photovoice (Wang and Burris, 1997). 19 of the 65 students worked on the theme of experiences of exclusion and inclusion at university and produced individual photo-stories and one collective book titled: 'The Bitter Truth of Success'. The individual photo-stories came out of three four-day workshops in Free State, Limpopo and Gauteng in which students received basic photography training, used River of Life drawings to reflect on their university experiences, and then produced storyboards on which they could base their photographs and narratives. They took their own photographs, curated, captioned and shared their individual stories, which had titles like 'My Journey of Thorns and Roses' and 'Thriving Through Tough Times' or 'Munwe muthihi a u tusi mathuthu' which is a Tshivenda proverb meaning 'One finger cannot pick up grain' and signifies the importance of collaborative effort to ensure success.

The photovoice process enabled students to demonstrate not only their linguistic capital (evident in their bi- or multilingualism, use of alliteration, similes, metaphors or African proverbs in titles of their photo-stories, or the captions for each photo) but their narrative capital too (evident in their ability to reflect on their life experiences and use this reflection to construct striking visual stories).

The following discussion draws on Rimisa's photo-story titled 'The Difference Between 'Here' and 'There' is Courage'. His story consists of 6 photographs that tell us about his experience of being at university, the hardship he has faced, but also his hope and aspirations for the furture. My analysis centres on the first (Image 1) and last photo (Image 2) in his story, because they reflect two important aspects in his narrative - his capacity to use symbolism in his reflection on his life story, and evidence of holding Ubuntu as a normative worldview. The importance of acknowledging both aspects is explained in the discussion that follows. 


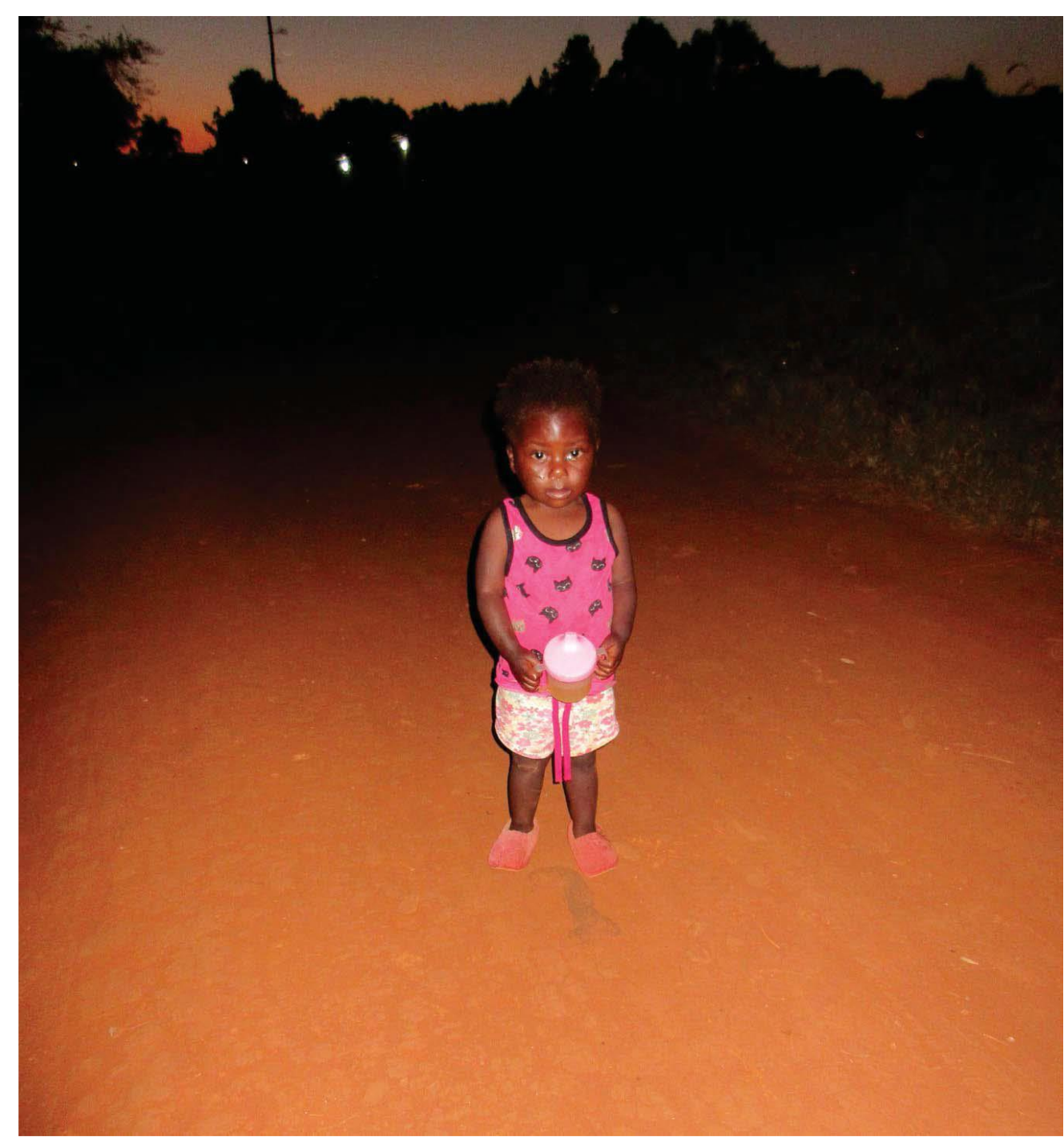

Image 1: The beginning of my journey at tertiary: I felt like a child who is lost in the street, because I was not familiar with the university and I experienced a lot of confusion.

In her research on students transition from school to university, Wilson-Strydom (2015) states that regardless of their home or schooling background, students who were just entering university felt 'confused, lost and scared'. Although this is hardly surprising because being at university means being in a new environment during a new stage of life, this adjustment should not hinder opportunities for first year students to participate in higher education (WilsonStrydom, 2015). Like Rimisa, many students in the Miratho project expressed these feelings in relation to navigating the physical landscape of the university - getting lost - and trying to grapple with how the university's systems work. Rimisa did not have access to the interpretive materials to render his experience intelligible by referring to Yosso's (2005) notion of navigational capital - the skills of manoeuvring through social institutions. That is, he could not describe his experience by saying 'I felt like I had no navigational capital' or 'I felt that I lacked the skills to manoeuvre through the university system'. Instead, he alludes to this by describing his experience as similar to that of 'a child who is lost in the street' because he was 'not familiar with the university' and therefore went through 'a lot of confusion'. In using the image of a 
child who appears alone in the middle of the street at night, Rimisa makes a symbolic reference to the disorientation he experienced when he first entered university, demonstrating the ability to reflect and make inferences to other examples of being lost and confused in the telling of his story.

While Rimisa's story does not begin well, the ending is more hopeful as it describes his aspirations. In contrast to the first image, this one is bright (taken in broad daylight) and more colourful.

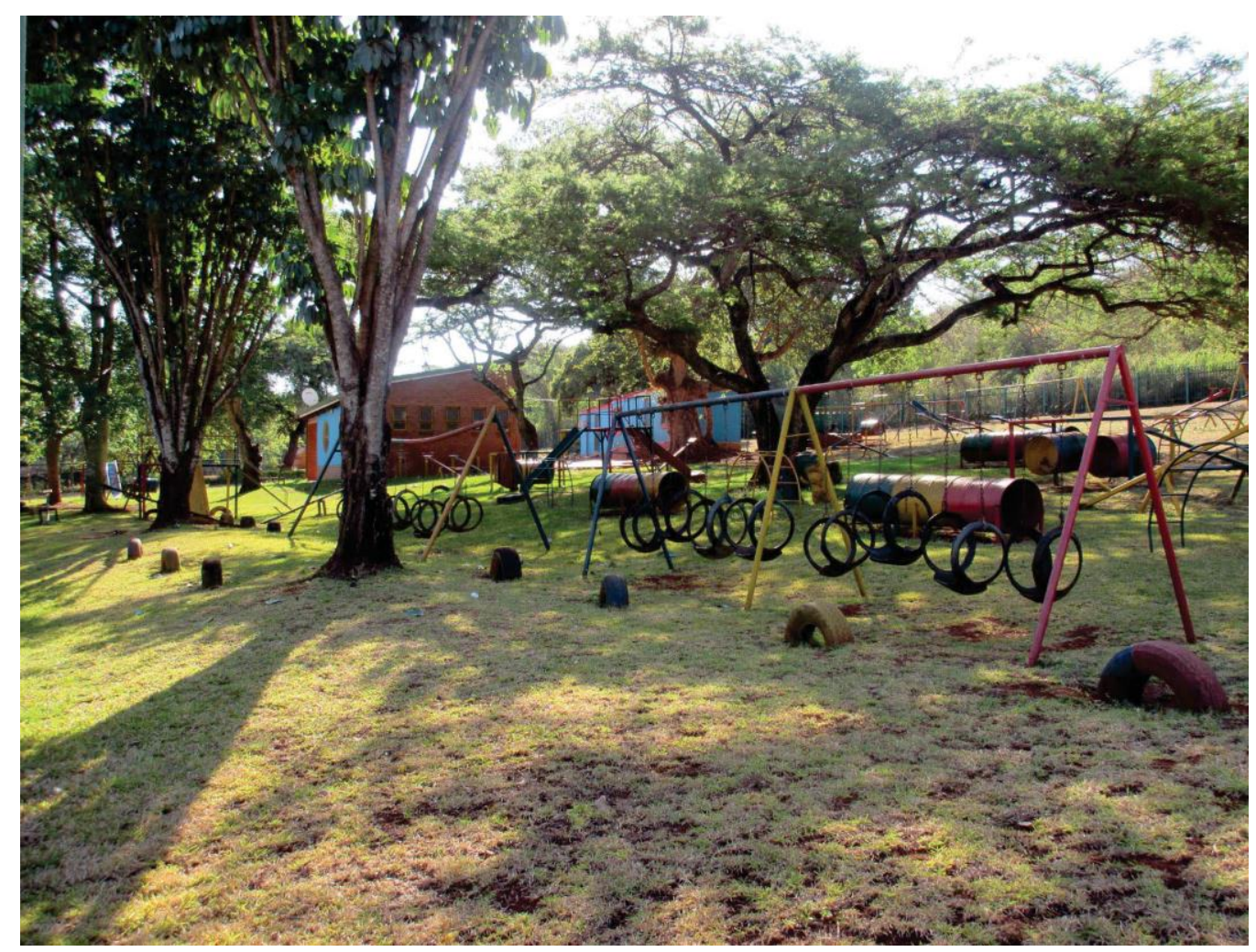

Image 2: My future plans: I want to build an orphanage home to help others who are poor because I do not want them to experience the struggles I experienced.

The caption tells us that Rimisa recognises the role of poverty in the hardships experienced by people like him, especially during their upbringing. It suggests that he sees the wellbeing of others as connected to his own wellbeing, in the sense that it is important to him and he would feel better knowing that fewer children will suffer as he did. It indicates that he feels morally obligated to contribute to the wellbeing of others. Rimisa also mentions wanting to give back to his community in his interviews:

I'm planning to help the youth of my community to be easy for them to access universities, information and information about let's say different bursaries. Yes. (2017 interview).

He has reiterated his ambitions to build an orphanage: 
I think it is the practice of helping others. So, like myself, I told myself okay, if I work, no, I'm going to work, I have to build an orphanage home so that they can have access to some basic needs. That is my own goal in life, my personal goal (2018 interview).

He has also spoken about wanting to experience success with others, instead of seeing himself as a competitor to his classmates:

I told myself that okay, if I comment [in class], someone will learn something from me, and that's what I want. Myself, I don't want to pass alone. Last year, when we were about to write examinations, I called all my students, all my colleagues, and I encouraged them to study very hard. I told them that yes, I am passing, but why should I be happy when I get 80 , whereas one or other students in my class are getting 30 ? So, I encouraged them to study very hard, and I am not alone who performs well in class.

We may see these excerpts as evidence of valuing Ubuntu - a Nguni ${ }^{4}$ word that is often translated as 'humanness to others' (Gianan, 2010). Another common way of describing Ubuntu is through the phrase 'I am only because we are, and since we are, I am' (du Toit, 2004: 33), or 'a person is a person through other persons' (Shutte, 1993: 46). Although it resists easy definition, it has been described variously as 'an age-old and traditional African world-view, a set of values or a philosophy of life which plays a strong and defining role in influencing social conduct' (Himonga et al., 2013: 367-7). Ubuntu implies that each person exists because others do, and that interaction between people necessarily involves mutuality and cooperation, to the extent that others' lives are the individual's life (Migheli, 2017). That is, it entails necessarily reciprocal interactions between individuals, which render us human (Tutu, 1999). As such, Ubuntu provides a 'unifying vision of community built upon compassionate, respectful, interdependent relationships' (Schwartz, 2009: 24) and serves as a rule of conduct, a social ethic, the moral and spiritual foundation for African societies (Molefe, 2016).

Conceiving of the world in Ubuntu terms implies a set of values and therefore practices that guide the life people want to lead. So, the practice of kindness to others can be seen as a process that begins with empathy and progresses to actions that enhance the wellbeing of others. Embodied empathy and the mediation of the feeling of responsibility for the wellbeing of others, guides and inspires Rimisa towards actions that can mitigate the discomfort, pain or needs experienced by other people (as expressed in his photo-story and interviews).

The last photo in Rimisa's visual narrative therefore speaks not only of one of his aspirations, but also of a worldview that is likely to be more prevalent in rural communities where mutual care and reciprocal support play pivotal roles in minimising everyday struggles associated with poverty.

${ }^{4} \mathrm{~A}$ group of languages including Xhosa, Zulu and Ndebele spoken in southern Africa by the Nguni people. 
With the discussion presented so far, I have illustrated how Rimisa's linguistic and narrative capital were converted into narrative functioning, which can be defined as sharing one's worldview and social and/or academic knowledge through storytelling using diverse languages or modes of telling stories. Importantly, the stories we tell are only validated when they are listened to. Similarly, the knowledge we share only becomes validated when it is acknowledged/valued. Thus conceived, the first step in creating social uptake conditions is the acknowledgement or recognition of the 'speaker' or storyteller as a trusted knower or creditable testifier.

\section{Reflections}

Traditional methods used in higher education research (e.g. interviews, questionnaires) may carry and represent the residual cultural presence of colonisation (Maldonado-Torres, 2007) particularly in terms of maintaining top-down, expert vs lay person or researcher vs research subject dichotomies that mirror power inequalities. This may occur even if interviews and questionnaires create spaces for researchers to gain knowledge from the views and experiences shared with them by research participants. In addition, educational research, but also teaching and learning in universities, is often done in ways that leave no room for reflective storytelling to take place, which limits the potential of transmitting social knowledge drawing on capitals that students already have. Through a capabilities lens, then, the effective opportunity to render one's story intelligible using the linguistic capital that one has reason to value, and to have it acknowledged is to be an epistemic contributor.

In contrast to traditional methods, participatory research can address misrecognition, which can ensure that more people who are stereotyped as lacking epistemic material are enabled to contribute to shared knowledge. Disrupting power and knowledge asymmetries through participatory research methods like photovoice is thus symbolic of de-linking from coloniality (Mignolo, 2007) as it allows for more equal participation between those who have power (researchers) and those who have less of it (research participants). Although many researchers have argued for addressing the power differentials in research particularly in South and North settings, addressing power differentials between university students and researchers or lecturers has distinctively decolonial value in the South African context because knowledge and social relations are typically produced in ways that silence marginal identities and voices (Behari-Leak and Mokou, 2019). This means that knowledge production through and within universities in South Africa reinforces inequalities in higher education that already linger in wider society due to coloniality or the legacies of apartheid. Therefore, acts of de-linking from coloniality create spaces for previously untrusted knowers to be listened to, because they highlight the importance of plurality, multiplicity, and difference (Dastile and Ndlovu-Gatsheni, 2013) in creating and sharing knowledge. They also undo the value hierarchies that have pushed African and indigenous worldviews to the margins of the university (Calitz, 2018b).

Because participatory research encourages the embrace of diverse voices, particularly those of the marginalised, it has a 'decolonial attitude' (Du Bois, 1999). Participatory methods 
like photovoice offer us possibilities to embrace ways of knowing and to consider the worldviews of people who are marginalised by structural inequalities. In other words, participatory methods make it possible to avoid testimonial injustice by encouraging us to recognise people who have typically been excluded from making epistemic contributions as credible knowers and trusted testifiers.

It is clear that low-income students who come from rural communities have capitals that can serve as epistemic material. However, these capitals can only become functionings once the effective opportunities to use them in the higher education space are in place. By incorporating photovoice in the Miratho project and being willing to listen to stories that students have reason to value and to tell, the research team widened the space for students' narrative and linguistic capitals (and perhaps their narrative modes of thought) to be mobilised as epistemic contributions. Returning to the role and function of the listener in knowledge creation - on the part of researchers, lecturers and university leaders- listening to students' stories is then equivalent to creating minimum uptake conditions for students' epistemic contributions.

As Gorski (2016) argues in his call to unhook from deficit and grit ideology and to strive for structural ideology in teacher education, lecturers' ideological positions determine their understandings of conditions such as socio-economic-based learning outcome disparities. Those understandings, in turn, determine the extent to which the teaching strategies lecturers can imagine have the potential to reduce or remove those disparities (Gorski, 2016). By abandoning deficit ideology and being open to different worldviews, critical reflections and inquiry, and embracing a collaborative culture and the will to learn from students, lecturers can also widen the space for students to mobilise their capitals into epistemic giving. This has the potential of bridging the gaps between the respective worlds students and lecturers draw on to make sense of the world, which requires ongoing negotiation and mediation, but also making explicit the 'rules and conventions' that determine what counts as knowledge (Boughey, 2005).

\section{Conclusion}

In this paper, I have argued that higher education researchers and educators ought to acknowledge the capitals students bring with them to university in order to facilitate the mobilisation of such capitals and foster epistemic contributions. In order to better understand the value of students' capitals in the higher education space, the capability approach was applied as an interpretive framework, which helped to conceptualise two distinct but interrelated capitals i.e. linguistic and narrative capital, as 'narrative capability'. Narrative capability was defined here as the effective opportunity to share one's worldview and social or academic knowledge through storytelling, using multiple languages and different modes of telling such stories. Using interview excerpts from Rimisa's life history interviews, and photos from his photo-story as a basis for my argument, I explained how narrative capability can be fostered through participatory research like photovoice. While the interview excerpts provided evidence of Rimisa's linguistic capital, the photo-story provided evidence of his narrative 
capital, as a way of demonstrating his ability to render his story intelligible using tools beyond his English language proficiency.

Through stereotypes and the abuse of social power in universities, students - in particular, those who are poor, black and come from rural communities with poorly resourced schools - are vulnerable to becoming victims of epistemic injustice. This happens because they usually seen as un/under-appreciated knowers, mistrusted testifiers, or because they are outsiders of the public economy of expertise and trustworthiness. However, with increasing numbers of low-income students in South African universities, and probably increasing numbers of students from rural communities, it is particularly important that we consider what capitals students bring with them into university, especially if we agree that the capitals are relevant sources of epistemic material. Looking for evidence of epistemic contribution from all and not just some students is one way of ensuring that universities (and higher education institutions) can or do foster the achievement of inclusive knowledge-making. As said before, questioning who is listened to, and who gets to contribute to knowledge, reveals the locus of epistemic relational equality and inequality. Unequal epistemic participation occurs when factors such as race or socio-economic class, to the detriment or silencing those who already suffer because of structural inequalities, e.g. low-income youth from rural communities, skews knowledge-making processes. Therefore, we might consider unequal epistemic participation in lecture halls, as a key mode in which unequal relationships and statuses within the higher education sector tend to manifest themselves.

To conclude, it is essential to identify the things (in this case misrecognition) that get in the way of epistemic contribution as they likely point to wider structures of inequality. If we care to create epistemic justice in the higher education space, we might begin by recognising poor rural youth as epistemic contributors with narrative capitals and narrative capability. This would symbolise a willingness to listen to those who are likely to be victims of testimonial injustice in higher education, signal an ethical response to structural inequalities that get in the way of university access for many, and suggest a decolonial stance in which the views and values of black South Africans are embraced in the academy.

\section{Acknowledgements}

My thanks to the project funders ESRC grant number ES/NO10094/1 and the NRF grant number 86540. My thanks to the members of the Miratho team, especially Melanie Walker and Monica McLean and also Carmen Martinez-Vargas. It is often hard in a research team to decide where one person's ideas end and the next begins - I am grateful for our many stimulating discussions about the project, about epistemic justice, and about participatory research. I am also grateful to Pablo Del Monte for drawing Watt's narrative capability to my attention. My thanks also to all the life history student participants and photovoice coresearchers from whom I continue to learn.

\section{Author Biography}


Mikateko Mathebula holds a PhD in Development Studies and is Senior Researcher at the SARCHI Chair's Higher Education and Human Development Research Programme at the University of the Free State in South Africa. Her research focuses on higher education's contribution in reducing inequalities and advancing social justice in and through universities. She has a particular interest in research that aligns with concerns about human flourishing, sustainability and inclusive knowledge-making processes developed in the global South.

\section{References}

Alkire, S. 2002. Dimensions of human development. World Development, 30 (2): 181-205.

Appadurai, A. 2006. The right to research. Globalisation, Societies and Education 4 (2): 167-177. Archer, L., Hutchings, M. \& Ross, A. (eds.). 2003. Higher Education and Social Class. Issues of Exclusion and Inclusion. London: Routledge.

Bathmaker, A-M., Ingram, N. A., Abrahams, J., Hoare, T., Waller, R. \& Bradley, H. 2016. Higher Education, Social Class and Social Mobility: The Degree Generation. London: Palgrave Macmillan.

Behari-Leak, K. \& Mokou, G. 2019. Disrupting metaphors of coloniality to mediate social inclusion in the global South. International Journal for Academic Development 24 (2): $135-147$

Boughey, C. 2005. Epistemological access to the university: An alternative perspective. South African Journal of Education 19 (3): 230-242

Bruner, J. 1985. Narrative and paradigmatic modes of thought. In J. Bruner (2006). In search of pedagogy. The selected works of Jerome Bruner. Vol. 2. New York: Routledge, 116-128.

Bruner, J. 1986. Actual Minds, Possible Worlds. Cambridge, MA: Harvard University Press.

Calitz, T. 2018. Recognition as reparation: A participatory approach to (mis)recognition and decolonisation in South African higher education. Educational Research for Social Change, 7(0): 46-59. DOI: http://dx.doi.org/10.17159/2221-4070/2018/v7i0a4

Calitz, T.M.L. 2018. Enhancing the Freedom to Flourish: Participation, Equality and Capabilities. London: Routledge

Coady, D. 2012. Two concepts of epistemic injustice. Episteme 7: 101-113

Coetze, T. S. 2018. Hermeneutical dissent and the species of hermeneutical injustice, Hypatia 33: $73-90$.

Crerar, C. 2016. Taboo, hermeneutical injustice, and expressively free environments. Episteme 13: 195-207.

Crocker, D.A. \& Robeyns, I. 2010. Capability and agency. In Morris, C. (ed.), Amartya Sen. Cambridge University Press.

Cross, M. \& Atinde, V. 2015. The pedagogy of the marginalised: Understanding how historically disadvantaged students negotiate their epistemic access in a diverse university environment. Review of Education, Pedagogy, and Cultural Studies 37 (4): 308-325.

Cross, M. 2018. Steering Epistemic Access in Higher Education in South Africa. Buenos Aires: CLACSO. 
Dastile, N.P. \& Ndlovu-Gatsheni, S. 2013. Power, knowledge and being: Decolonial combative discourse as a survival kit. Alternation 20 (1): 105-134.

Dotson, K. 2012 A cautionary tale on limiting epistemic oppression frontiers. Journal of Women Studies 33 (1):24-47.

Du Bois, W.E.B. 1999. The souls of black folk. In Gates Jr, H.L. \& Oliver, T.H. (Eds.). Authoritative Text. Contexts. Criticisms. New York: W. W. Norton \& Co 2-416.

Dworkin, R. 2002. Sovereign Virtue: The Theory and Practice of Equality. Harvard: Harvard University Press.

Freire, P. 1973. Education for Critical Consciousness. New York: Continuum.

Fricker, M. 2015. Epistemic contribution as a central human capability. In Hull, G. (ed.). The Equal Society. London: Lexington Books, 73-91.

Goodson, I. \& Sikes, P. 2001. Life History Research in Educational Settings_Learning from Lives. Buckingham: Open University Press.

Gorski, P.C. 2016. Poverty and the ideological imperative: a call to unhook from deficit and grit ideology and to strive for structural ideology in teacher education. Journal of Education for Teaching 42 (4): 378-386. DOI: http://dx.doi.org/10.1080/02607476.2016.1215546

Harper, D. 2002. Talking about pictures: A case for photo elicitation. Visual Studies 17 (1): 1326.

Jack, A. 2019. The Privileged Poor: How Elite Universities are Failing Disadvantaged Students. Harvard: Harvard University Press.

Janse van Rensburg, V. \& Kapp, R. 2015. 'So I have to be positive, no matter how difficult it is': A longitudinal case study of a first-generation Occupational Therapy student. South African Journal of Occupational Therapy 44 (3): 29-33.

Jones, J.D. 2004. Succeeding by any means necessary. Black Issues in Higher Education 21 (12): $0-4$.

Kegan, R. 2009. What form transforms? A constructive- developmental approach to transformative learning. In Illeris, K. (ed.). Contemporary Theories of Learning: Learning Theorists in Their Own Words. London: Routledge, 35-52.

Leonard, M. \& McKnight, M. 2015. Look and tell: Using photo-elicitation methods with teenagers, Children's Geographies 13 (6): 629-642, DOI: 10.1080/14733285.2014.887812

Maldonado-Torres, N. 2007. The coloniality of being. Cultural Studies 21 (2): 240-270.

Marion, J.S. \& Crowder, J.W. 2013. Visual Research: A Concise Introduction to Thinking Visually. London: Bloomsbury.

Marshall, D. \& Case, J. M. 2010. Rethinking 'disadvantage' in higher education: A paradigmatic case study using narrative analysis. Studies in Higher Education 35 (5): 491-504.

Martinez-Vargas, C., Walker, M. \& Mkwananzi, F. 2019. Access to higher education in South Africa: Expanding capabilities in and through an undergraduate photovoice project, Educational Action Research. DOI: 10.1080/09650792.2019.1612767

Mason, R. 2011. Two kinds of unknowing. Hypatia 26: 294-307. 
Mathebula, M. 2018. Engineering Education for Sustainable Development: A Capabilities Approach. London: Routledge.

Metcalf, M. 2019. Forget the matric ballyhoo and focus on the real issues that need fixing. Sunday Times, 6 January 2019. Accessed 3 May 2019 from: https://www.timeslive.co.za/sunday-times/opinion-and-analysis/2019-01-06-forgetthe-matric-ballyhoo-and-focus-on-the-real-issues-that-need-fixing/

Mezirow, J. 2000. Learning as Transformation: Critical Perspectives on a Theory in Progress. San Francisco: Jossey-Bass.

Mignolo, W. 2007. Delinking: The rhetoric of modernity, the logic of coloniality and the grammar of decoloniality. Cultural Studies 21 (2-3): 449-514.

Mikhailovich, K., Pamphilon, B. \& Chambers, B. 2015 Participatory visual research with subsistence farmers in Papua New Guinea, Development in Practice 25 (7): 997-1010, DOI: 10.1080/09614524.2015.1069260

Mkwananzi, F. 2019. Higher Education, Youth and Migration in Contexts of Disadvantage: Understanding Aspirations and Capabilities. London: Palgrave McMillan.

Molefe, M. 2016. African ethics and partiality. Phronimon,17 (2) Pretoria.DOI: http://dx.doi.org/10.17159/2413-3086/2016/142

Morrow, W. 2009. Bounds of Democracy: Epistemological Access in Higher Education Cape Town: Human Science Research Council (HSRC) Press

Moses, E., Van der Berg, S. \& Rich K. 2017. A Society Divided. How Unequal Education Quality Limits Social Mobility in South Africa. Synthesis Report for the Programme to Support Pro-Poor Policy Development (PSPPD). Stellenbosch, South Africa: University of Stellenbosch.

Mutanga, O. 2019. Students with Disabilities and the Transition to Work: A Capabilities Approach. London: Routledge.

Ndlovu-Gatsheni, S.J. 2018. Epistemic Freedom in Africa. Deprovincialization and Decolonization. New York: Routledge.

Oana, P. 2016. Using participatory, visual and biographical methods with Roma youth. Forum: Qualitative Social Research 17 (1): Article 5.

Phelps T.G. 2006. Narrative Capability: Telling Stories in the Search for Justice. In: Deneulin S., Nebel M., Sagovsky N. (eds) Transforming Unjust Structures: The Capability Approach. Library of Ethics and Applied Philosophy, Vol. 19. Springer, Dordrecht.Pohlhaus, G. 2011. Relational knowing and epistemic injustice: Toward a theory of willful hermeneutical ignorance. Hypatia 1127 (4): 715-35.

Rawls, J.B. 1971. A Theory of Justice. Cambridge, Massachusetts: Belknap Press of Harvard University Press.

Robeyns, I. 2005. The Capability Approach: A theoretical survey. Journal of Human Development 6 (1): 93-114.

Sayer, A. 2005. The Moral Significance of Class. Cambridge: Cambridge University Press. 
Schwartz, S. 2009. The Moral Ecology of South Africa's Township Youth. Basingstoke: Palgrave Macmillan.

Sen, A. 1999. Development as Freedom. Oxford: Oxford University Press.

Soudien, C. 2007. The "A" factor: Coming to terms with the question of legacy in South African education. International Journal for Academic Development 27 (2): 182-193.

Sulla, V. \& Zikhali, P. 2018. Overcoming Poverty and Inequality in South Africa: An Assessment of Drivers', Constraints and Opportunities (English). Washington, D.C.: World Bank Group.

Timmis, S. \& Muhuro, P. 2019: De-coding or de-colonising the technocratic university? Rural students' digital transitions to South African higher education. Learning, Media and Technology, DOI: https://doi.org/10.1080/17439884.2019.1623250

Walker, M. 2008. Widening participation; widening capability. London Review of Education 6 (3): 267-279.

Walker, M. 2019. Defending the need for a foundational epistemic capability in education, Journal of Human Development and Capabilities 20 (2): 218-232, DOI: 10.1080/19452829.2018.1536695

Walker, M. \& Mathebula, M. 2019. Low-income rural youth migrating to urban universities in South Africa: opportunities and inequalities. Compare: A Journal of Comparative and International Education, DOI: 10.1080/03057925.2019.1587705

Wang, C.C. \& Burris, M.A. 1994. Empowerment through photo novella: Portraits of participation. Health, Education and Behaviour 21 (2): 171-186.

Wang, C.C. \& Burris, M.A. 1997. Photovoice: Concept, methodology, and use for participatory needs assessment. Health Education and Behavior 24: 369-387.

Watts, M. 2008. Narrative research, narrative capital, narrative capability. In Satterwaithe, J. Watts, M. \& Piper, H. (Eds.). Talking Truth, Confronting Power. Stoke-on-Trent: Trentham Books. 99-112.

Wilson-Strydom, M. 2015. University Access and Success: Capabilities, Diversity and Social Justice. London: Routledge.

Young, I. M. 1990. Justice and the Politics of Difference. Princeton, New Jersey: Princeton University Press. 